\title{
Very low prevalence of germline MSH6 mutations in hereditary non-polyposis colorectal cancer suspected patients with colorectal cancer without microsatellite instability
}

\author{
CM Kets ${ }^{*, 1}$, JHJM van Krieken², KM Hebeda ${ }^{2}$, SJ Wezenberg', M Goossens ${ }^{1,2}$, HG Brunner', MJL Ligtenberg ${ }^{1,2}$ \\ and N Hoogerbrugge'
}

'Department of Human Genetics, Radboud University Nijmegen Medical Centre, 849 Human Genetics, PO Box 9101 , 6500 HB Nijmegen, The Netherlands; ${ }^{2}$ Department of Pathology, Radboud University Nijmegen Medical Centre, The Netherlands

Hereditary non-polyposis colorectal cancer (HNPCC) is caused by mutations in one of the mismatch repair genes MLHI, MSH2, MSH6, or PMS2 and results in high-level microsatellite instability (MSI-high) in tumours of HNPCC patients. The MSI test is considered reliable for indicating mutations in $\mathrm{MLHI}$ and $\mathrm{MSH2}$, but is questioned for $\mathrm{MSH6}$. Germline mutation analysis was performed in 19 patients with an MSI-high tumour and absence of MSH2 and/or MSH6 protein as determined by immunohistochemistry $(\mathrm{IHC})$, without an MLHI or MSH2 mutation, and in 76 out of 295 patients suspected of HNPCC, with a non-MSI-high colorectal cancer (CRC). All 295 non-MSI-high CRCs were analysed for presence of MSH6 protein by IHC. In 10 patients with an MSI-high tumour without MSH2 and/or MSH6 expression, a pathogenic MSH6 mutation was detected, whereas no pathogenic MSH6 mutation was detected in 76 patients with a non-MSI-high CRC and normal MSH6 protein expression. In none of the 295 CRCs loss of MSH6 protein expression was detected. The prevalence of a germline MSH6 mutation is very low in HNPCC suspected patients with non-MSI-high CRC. Microsatellite instability analysis in CRCs is highly sensitive to select patients for MSH6 germline mutation analysis.

British Journal of Cancer (2006) 95, 1678 - 1682. doi: 10. I038/s.bjc.6603478 www.bjcancer.com

Published online 2I November 2006

(c) 2006 Cancer Research UK

Keywords: MSI; HNPCC; hereditary cancer, MSH6

Hereditary non-polyposis colorectal cancer syndrome (HNPCC) is an autosomal-dominant inherited disorder predisposing to colorectal cancer (CRC) and several other cancers at an early age, including endometrial carcinoma. It is clinically suspected by Amsterdam criteria and Bethesda guidelines (Rodriguez-Bigas et al, 1997; Umar et al, 2004). Hereditary non-polyposis colorectal cancer is caused by mutations in one of the mismatch repair (MMR) genes ( $M L H 1, M S H 2, M S H 6$, and PMS2) and is characterised by tumours that show microsatellite instability (MSI). Failure of MMR results in MSI especially in short repetitive sequences. Molecular testing for HNPCC can be performed by testing tumours for MSI and absence of MLH1, PMS2, MSH2 and/ or MSH6 as determined by immunohistochemistry (IHC), and germline mutation analysis of MMR genes.

In clinical practice MSI analysis is used as a prescreening tool to select families for further analysis of MMR gene defects. Germline mutations in the MSH6 MMR gene account for approximately $15-30 \%$ of cases of HNPCC (Hampel et al, 2005; Barnetson et al, 2006; Niessen et al, 2006). However MSH6 mutation carriers were reported to have tumours without an MSI-high pattern (Berends

*Correspondence: Dr CM Kets; E-mail: m.kets@antrg.umcn.nl Received I 3 July 2006; revised 10 October 2006; accepted II October 2006; published online 21 November 2006 et al, 2002; Hendriks et al, 2004; Plaschke et al, 2004), whereas in MLH1 and MSH2 mutation carriers almost all HNPCC-associated tumours show MSI (Lynch and Lynch, 2005). The reliability of MSI analysis to select patients at risk for MSH6 mutations is therefore questioned. As germline mutation analysis and IHC of MMR proteins is almost exclusively initiated when MSI analysis shows MSI, we might miss MSH6 germline mutations.

The aim of this study was to establish the prevalence of MSH6 mutations in HNPCC suspected patients without MSI in their tumours to investigate the value of MSI analysis to detect MSH6 mutations.

\section{MATERIALS AND METHODS}

The study is based on 617 tumours of patients or their family members suspected of HNPCC that visited our clinical genetics department in which MSI and subsequent analyses were performed between 1997 until 2006 (Figure 1). In the families analysed in our study MSI analysis is performed in the tumour of the youngest relative available. All findings in this group that were available at 1-1-2006 are included in this study. In 529 tumours of patients a reliable distinction between MSI-high and MSI-stable/low could be made using the standard set of markers (Boland et al, 1998). IHC of MMR proteins became available and was applied for from 1999, 


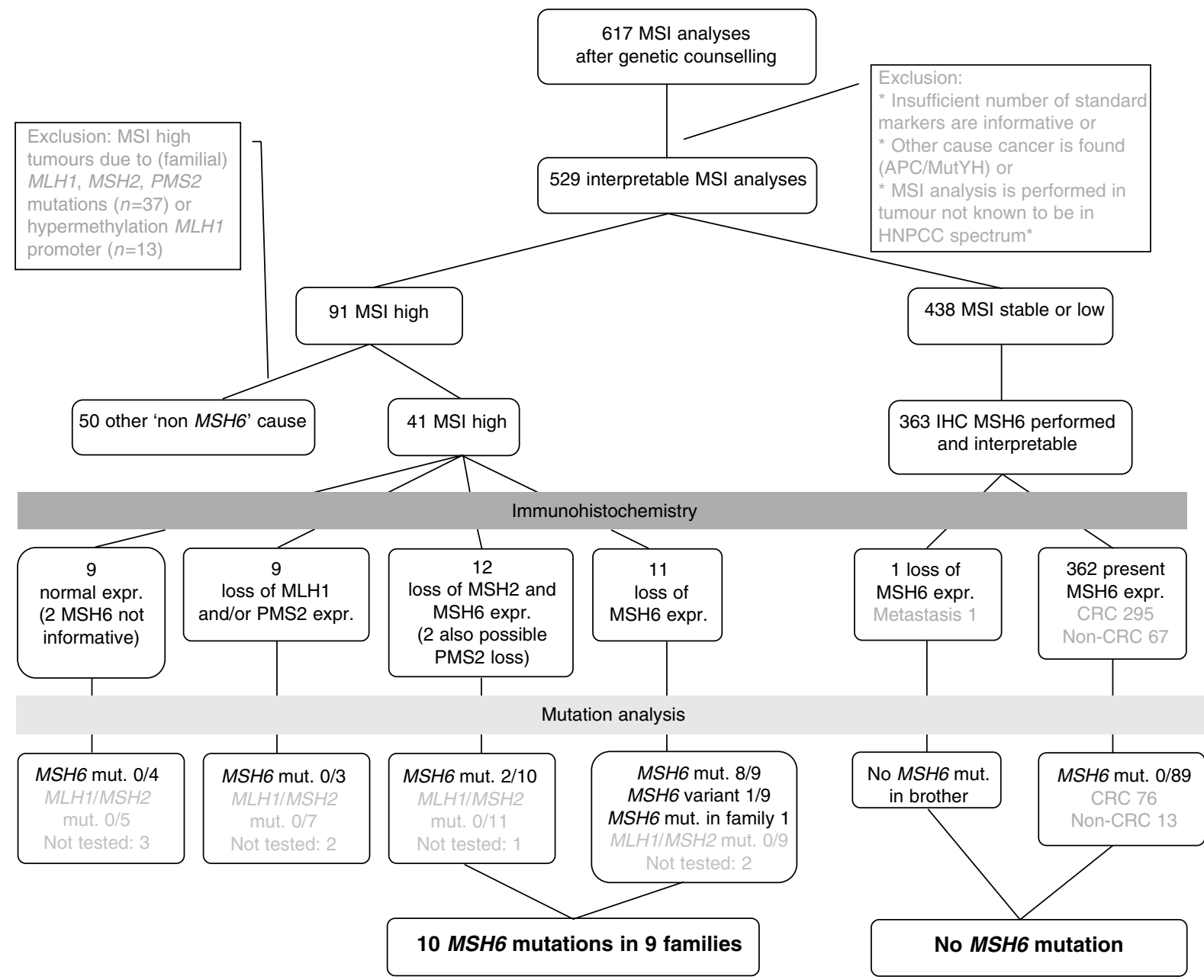

Figure I Flowchart MSI analyses. *HNPCC spectrum: CRC, endometrial cancer, sebaceous carcinoma, urothelial cell carcinoma, and brain tumour. MSH6 mut: found pathogenic MSH6 mutations vs number of patients in which MSH6 was analysed; MLHI IMSH2 mut: found pathogenic MLHI /MSH2 mutations vs number of patients in which $\mathrm{MLHI}$ and $\mathrm{MSH} 2$ were analysed; not tested: number of patients in which no mutation analyses were performed.

in some cases retrospectively. IHC of the MSH6 protein was performed in all tumours regardless of MSI results. IHC of all MMR proteins was performed in case of an MSI- high or MSI-low tumour or when other tissue than CRC was tested, such as endometrial cancer, gastric cancer, sebaceous carcinoma, urothelial cell carcinoma, and brain tumours (Rodriguez-Bigas et al, 1997). We focused on two separate cohorts of patients; patients with and without MSI in their tumour DNA. The pedigrees made as a part of the genetic counselling procedure were studied for fulfilment of Amsterdam II criteria and Bethesda guidelines (Rodriguez-Bigas et al, 1997; Umar et al, 2004).

The study was performed according to the rules of the Medical Ethics Committee of the Radboud University Nijmegen Medical Centre.

\section{Molecular analysis}

For MSI analysis normal and tumour tissues were extracted from formalin- fixed and paraffin-embedded tissues. The Bethesda microsatellite panel D2S123, D5S346, D17S250, BAT25, and BAT26 (Boland et al, 1998) was used essentially according to methods described previously (Hoogerbrugge et al, 2003). A tumour was considered MSI-high when instability was found in $\geqslant 2$ out of five markers $(n=91)$ and MSI-stable or low in case of instability in $\leqslant 1$ out of five markers $(n=438)$. In 178 samples the mononucleotide marker BAT40 was included in the standard marker set. IHC of the
MMR proteins was performed with the monoclonal antibodies against MSH6 (Transduction lab code: G70220), MLH1 (Pharmingen code: 51-1327gr), PMS2 (Pharmingen code: 556415), and MSH2 (Oncogene code: NA26). Germline MSH6 mutation analysis of the coding regions and splice sites of the MSH6 gene was performed with a combination of sequence analysis (exon 1, splice acceptor site of exon 10), one-dimensional denaturing gradient gel electrophoresis (exons 2 up to and including 10) essentially as described by Wu et al (1999) and multiplex ligation-dependent probe amplification (MRC Holland) for the detection of exon deletions and duplications (exon 1 to 10). Only changes located within 10 nucleotides of the coding region that have not been described as polymorphisms before, are reported.

\section{Patients with an MSI-high tumour}

MSH6 germline mutation analysis was performed in a group of 19 patients with MSI-high HNPCC-associated tumours and loss of MSH6 expression in which $M L H 1$ and $M S H 2$ mutations were excluded. Nine of these tumours showed loss of MSH6 expression in the presence of $\mathrm{MSH} 2$ expression and 10 showed loss of both MSH2 and MSH6 expression, of which two were difficult to interpret and possibly also showed loss of PMS2 expression. Microsatellite instability patterns of HNPCC-associated tumours of $12 \mathrm{MLH1}, 22 \mathrm{MSH} 2$, and $10 \mathrm{MSH} 6$ mutation carriers were studied to compare the instability patterns of tumours of patients with 
germline mutations in MSH6 to those with germline mutations in $M L H 1$ and $M S H 2$.

\section{Patients with a non-MSI-high tumour}

Three hundred and sixty-three non-MSI-high HNPCC-associated tumours (295 CRC) were analysed out of 335 families. Patients most suspected of HNPCC were selected by fulfilment of at least one of the following criteria; (1) age at diagnosis below 50 years, (2) first degree relative with an HNPCC-related tumour, or (3) second CRC. Of the patients that fulfilled one or more of these criteria a subgroup of 89 patients, 76 of whom had CRC, and one first degree relative, were analysed for MSH6 germline mutations.

\section{Statistical analysis}

Categorical variables were compared with the use of the Fisher's exact test using SPSS, version 12.0. A $P$-value of 0.05 is considered as threshold for statistical significance.

\section{RESULTS}

\section{MSH6 mutation analysis in patients with an MSI-high tumour}

In a group of 19 patients with both an MSI-high HNPCCassociated tumour and loss of MSH6 expression, but no detectable defect in $M L H 1$ or $M S H 2,10$ pathogenic mutations in MSH6 were found in nine families (Table 1). Besides the nine different MSH6 germline mutations found in patients with an MSI-high tumour, two pathogenic mutations in MSH6 were found in patients in whom MSI analysis could not be performed. The mean age at diagnosis of the 11 index patients from the families with a pathogenic MSH6 mutation was 44 years (range 36-57). The MSI analyses in nine of these index patients with an MSH6 mutation was performed on four endometrial, four colorectal, and one urothelial cell cancer. All MSH6 mutation carriers fulfil one or more Bethesda guidelines and in $64 \%$ of the families the Amsterdam II criteria are fulfilled. In the MSH6 families endometrial cancers occur as frequently as CRCs.

Of the remaining nine tumours with loss of MSH6 expression, eight tumours also showed loss of MSH2 expression of which two were difficult to interpret and possibly showed loss of PMS2 expression as well, suggesting the presence of an as yet undetected MSH2 (or PMS2) germline mutation. One tumour, a CRC developed at age 53, exclusively showed loss of the MSH6 protein. In this female patient an MSH6 variant c.2117T > C (p.Phe706Ser) was found of which the pathogenicity is uncertain. She also carries a pathogenic mutation in BRCA2 (c.3269del (p.Met1080fs)). The patients' mother carries the same MSH6 variant but not the BRCA2 mutation. She was diagnosed with endometrial cancer at age 62 . Microsatellite instability analysis and IHC on her tumour were inconclusive.

Stability in one or more of the dinucleotide markers occurred significantly more often in colorectal tumours of $\mathrm{MSH6}$ than of MLH1 and MSH2 mutation carriers (Table 2). Stability of

Table I Characteristics of patients with a germline mutation in MSH6

\begin{tabular}{|c|c|c|c|c|c|c|c|c|c|c|}
\hline \multirow{2}{*}{$\begin{array}{l}\text { Tested cancer } \\
\text { and age at } \\
\text { diagnosis }\end{array}$} & \multirow{2}{*}{$\begin{array}{l}\text { Pathogenic } \\
\text { mutation MSH6 }\end{array}$} & \multicolumn{2}{|c|}{ MSI high } & \multirow[b]{2}{*}{$\begin{array}{l}\text { IHC } \\
\text { MSH6 }\end{array}$} & \multirow[b]{2}{*}{$\begin{array}{l}\text { IHC } \\
\mathrm{MSH2}\end{array}$} & \multirow[b]{2}{*}{$\begin{array}{l}\text { Amsterdam } \\
\text { criteria II }\end{array}$} & \multirow[b]{2}{*}{$\begin{array}{c}\text { Bethesda } \\
\text { A }\end{array}$} & \multirow[b]{2}{*}{$\begin{array}{c}\text { Bethesda } \\
\text { B }\end{array}$} & \multirow[b]{2}{*}{$\begin{array}{l}\text { EN in } \\
\text { family }\end{array}$} & \multirow[b]{2}{*}{$\begin{array}{l}\text { CRC in } \\
\text { family }\end{array}$} \\
\hline & & $\begin{array}{c}\text { Instable } \\
\text { mono-nucleotides }\end{array}$ & $\begin{array}{c}\text { Instable } \\
\text { di-nucleotides }\end{array}$ & & & & & & & \\
\hline $\mathrm{CO} 42$ & c.265-?_457+?dup & $2 / 3$ & $2 / 3$ & Neg & Pos & + & - & + & + & + \\
\hline $\mathrm{EN} 57^{\mathrm{a}}$ & c.8|4G > T (p.Glu272X) & $3 / 3$ & $0 / 3$ & Neg & Pos & + & - & + & + & + \\
\hline $\mathrm{CO} 52^{\mathrm{b}}$ & c.65I dup (p.Lys2। 8X) & $2 / 2$ & $3 / 3$ & Neg & Pos & + & + EN 37 & + & + & + \\
\hline $\cos 58^{b}$ & c.65 I dup (p.Lys2 I 8X) & $3 / 3$ & $2 / 3$ & Neg & Neg & + & $+\mathrm{CO} 60$ & + & + & + \\
\hline EN 36 & c.3838C > T (p.Gln|280X) & $2 / 2$ & $1 / 3$ & Neg & Pos & + & - & + & + & + \\
\hline $\mathrm{CO} 50$ & c.3273dup (p.Lys |092X)) & $2 / 2$ & $2 / 3$ & Neg & Pos & + & $+\mathrm{CO} 46 / \mathrm{CO} 50$ & + & + & + \\
\hline EN 43 & c.326Idup (p.Phel088fs) & $2 / 2$ & $3 / 3$ & Neg & Neg & + & - & + & + & - \\
\hline $\mathrm{CO} 39$ & c.326I del (p.Phel088fs) & $2 / 2$ & $2 / 3$ & Neg & Pos & + & - & + & - & + \\
\hline EN 38 & c.||35_||39del (p.Arg379X) & $2 / 2$ & $1 / 3$ & Neg & Pos & - & $+\bigcirc 38$ & - & + & - \\
\hline UR 56 & c. I-?_475+? del & $3 / 3$ & $0 / 3$ & Neg & Pos & - & +UR 57SEB 59 & + & - & + \\
\hline EN 38 & c.3678_3706dup (p.Ala I236fs) & nt & & nt & nt & - & - & + & + & - \\
\hline $\mathrm{CO} 47$ & c. $2815 \bar{C}>T(p . G \ln 939 X)$ & $n t^{c}$ & & $\mathrm{nt}$ & $\mathrm{nt}$ & - & - & + & - & + \\
\hline Total & & & & & & $\begin{array}{l}7 / 11 \\
(64 \%)\end{array}$ & $\begin{array}{l}4 / 11 \\
(36 \%)\end{array}$ & $\begin{array}{l}10 / 11 \\
(91 \%)\end{array}$ & $\begin{array}{l}8 / 11 \\
(73 \%)\end{array}$ & $\begin{array}{l}8 / 11 \\
(73 \%)\end{array}$ \\
\hline
\end{tabular}

Bethesda A: Proband with two HNPCC-related cancers, Bethesda B: Proband and first degree relative with HNPCC-related cancer, one diagnosed $<50$ y. EN = endometria cancer, $\mathrm{CO}=$ colorectal cancer, $\mathrm{UR}=$ urothelial cell carcinoma, $\mathrm{SEB}=$ sebaceous adenoma, $\mathrm{O}=$ ovarian cancer, Neg $=$ negative, Pos $=$ positive, $\mathrm{nt}=\mathrm{not}$ tested $\mathrm{IHC}=$ immunohistochemistry; $\mathrm{MSI}=$ microsatellite instability. ${ }^{\mathrm{a}}$ This patient also has an UV c.65G $>\mathrm{C}$ (p.Gly22Ala) in MLHI ${ }^{\mathrm{b}} \mathrm{Patients}$ from same family. ${ }^{\mathrm{C}}$ Tumour of patients father showed MSI and no MSH6 expression.

Table 2 Results of the MSI analysis in MSH6, MLHI and MSH2 mutation carriers

\begin{tabular}{|c|c|c|c|}
\hline MSI pattern & MSH6 mutation carriers & $M L H I$ and $M S H 2$ mutation carriers & $P$-value Fisher exact \\
\hline \multicolumn{4}{|c|}{ One or more of three dinucleotides ${ }^{\mathrm{a}}$ stable } \\
\hline CRC & $4 / 5(80 \%)$ & $4 / 22(18 \%)$ & 0.017 \\
\hline Non CRC & $4 / 5(80 \%)$ & $1 / 6(17 \%)$ & NS \\
\hline \multicolumn{4}{|c|}{ One or more mononucleotides ${ }^{b}$ stable } \\
\hline CRC only & I/5 (20\%) & $2 / 26(8 \%)$ & NS \\
\hline Non CRC & $0 / 5(0 \%)$ & $0 / 6(0 \%)$ & NS \\
\hline
\end{tabular}

NS = not significant; $C R C=$ colorectal cancer; $M S I=$ microsatellite instability. ${ }^{a}$ D2SI23, D5S346, and DI7S250. ${ }^{b}$ BAT25 and BAT26. 
mononucleotide markers is uncommon in tumours of MSH6 as well as $M L H 1$ and $M S H 2$ mutation carriers.

\section{MSH6 mutation analysis in patients with a non-MSI-high tumour}

Immunohistochemical staining showed MSH6 expression in all 295 non-MSI-high CRCs and in 67 out of 68 other non-MSI-high HNPCC-related tumours (Table 3).

A subgroup of patients with the highest suspicion of HNPCC, was tested for the presence of MSH6 germline mutations. In none of the 76 patients with CRC, or in the 13 patients with other HNPCC-related tumours a pathogenic germline mutation in MSH6 was detected. One non-MSI-high tumour of metastatic tumour tissue (most probably derived from a CRC) of a deceased patient showed loss of MSH6 expression, in presence of MLH1 and MSH2 expression. Because mutation analysis could not be performed in the deceased patient, mutation analysis in her brother was performed. No mutation in MSH6 was detected (Table 4).

Silent variants c.3852G $>$ A, c. $2154 \mathrm{C}>\mathrm{T}, \quad$ c. $1068 \mathrm{~T}>\mathrm{C}$, and c.3246G $>$ T were found. None of these are predicted to affect splicing and thus do not seem to have functional consequences. The missense variant c.3101G >C (p.Arg1034Pro) that was found

Table 3 Overview of microsatellite stable/low tumours

\begin{tabular}{|c|c|c|c|}
\hline & $\begin{array}{c}\text { Patient with } \\
\text { non-MSI-high } \\
\text { tumour and loss } \\
\text { of MSH6 } \\
\text { expression }\end{array}$ & $\begin{array}{l}\text { Patients with } \\
\text { non-MSI-high } \\
\text { tumours and } \\
\text { positive MSH6 } \\
\text { expression }\end{array}$ & $\begin{array}{c}\text { Selected group } \\
\text { of patients with } \\
\text { non-MSI-high } \\
\text { tumours and } \\
\text { positive MSH6 } \\
\text { expression } \\
\text { without a } \\
\text { pathogenic } \\
\text { mutation in } \\
\text { MSH6 }\end{array}$ \\
\hline Colorectal ca & & 295 & 76 \\
\hline Age $<50$ yr & & |7| (58\%) & $62(82 \%)$ \\
\hline $\begin{array}{l}\text { Other HNPCC- } \\
\text { related neoplasia }\end{array}$ & I & 67 & 13 \\
\hline Endometrial ca & & 15 & 3 \\
\hline Gastric ca & & 3 & \\
\hline Sebaceous ca & & 4 & \\
\hline Urothelial cell ca & & 1 & \\
\hline Brain tumour & & I & \\
\hline Metastatic tissue & $1^{a}$ & 7 & \\
\hline Small bowel & & I & \\
\hline \multicolumn{4}{|l|}{ Adenoma } \\
\hline Colon & & 34 & 10 \\
\hline Duodenum & & 1 & \\
\hline Age $<50 \mathrm{yr}$ & 0 & $34(5 \mid \%)$ & $9(69 \%)$ \\
\hline
\end{tabular}

$\mathrm{MSI}=$ microsatellite instability; HNPCC = hereditary non-polyposis colorectal cancer;

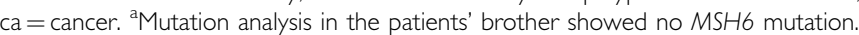

in a female patient with CRC at age 43 might be pathogenic. As the carcinoma was not available the MSI and IHC analyses were performed in an adenoma, which might have decreased the sensitivity of the analyses. Segregation analysis in the family showed that her brother who had a glioma, and the mother who had two sisters with anamnestic endometrial cancer did not carry the MSH6 variant, making the pathogenecity of this variant less likely.

\section{DISCUSSION}

In this study, not one pathogenic germline MSH6 mutation was detected in HNPCC suspected patients with a non-MSI-high CRC or HNPCC-related tumour.

Previous studies suggested that the sensitivity of MSI analysis to predict an MSH6 mutation is low and that MSI should not be used as a selection criterion for MSH6 mutation analysis (Wu et al, 1999 ), finding microsatellite stable or low patterns in $17 \%$ up to 50\% (Berends et al, 2002; Hendriks et al, 2004; Plaschke et al, 2004; Niessen et al, 2006; Pinto et al, 2006) of HNPCC-associated tumours of MSH6 mutation carriers. However careful consideration of previous studies is required as part of the conclusions are based on MSH6 missense mutations of unknown pathogenecity or testing a sporadic tumour within an HNPCC family (a phenocopy) as suggested by positive immunostaining of MSH6 in the tumour. These have an unfavourable effect on the sensitivity of MSI analysis. In addition MSI analysis on endometrial cancer, the most frequent tumour in female MSH6 mutation carriers might decrease its sensitivity, as it is known that the instability in these tumours is generally less pronounced (Wijnen et al, 1999; Hendriks et al, 2004).

MSH6 mutations result in a weaker mutator phenotype (Kolodner et al, 1999), which may be explained by the major function of MSH6 to correct base-base mismatches and single nucleotide deletion loops but not larger deletion loops (Parc et al, 2000). Like in previous studies (Kolodner et al, 1999; Verma et al, 1999; Parc et al, 2000) our study shows that mononucleotide markers but not dinucleotide markers are sensitive to show instability in tumours of MSH6 mutation carriers. The sensitivity of MSI analysis therefore depends on the microsatellite markers used. Enlarging the standard (Bethesda) marker set (Boland et al, 1998 ) with a mononucleotide marker (like BAT40) will increase the sensitivity of MSI analysis by minimising the chance of missing tumours with MSH6 inactivation. As data on MSI analysis of other non-colorectal HNPCC-related tumours with defective MMR are insufficient, we recommend additional IHC of MLH1, PMS2, MSH2, and MSH6 proteins when MSI analysis is performed on non-colorectal HNPCC-related cancers. Immunohistochemical staining of MMR proteins will also improve the interpretation of MSI patterns when a low percentage of tumour cells or an adenoma is tested or when only one mononucleotide marker shows instability (MSI low). When a patient is excluded from further HNPCC analysis based on a non-MSI-high pattern in

Table 4 MSI-test result and IHC protein expression pattern of tumours from patients tested for the presence of a MSH6 germline mutation

\begin{tabular}{|c|c|c|c|c|c|}
\hline \multicolumn{2}{|l|}{ MSI } & \multicolumn{2}{|c|}{ MSI high } & \multicolumn{2}{|c|}{ MSI stable/low } \\
\hline No pathogenic mutation in MSH6 & $1^{\mathrm{b}}$ & 6 & 2 & $I^{c}$ & 89 \\
\hline Pathogenic mutation in $\mathrm{MSH} 6$ & 8 & 2 & & & \\
\hline
\end{tabular}

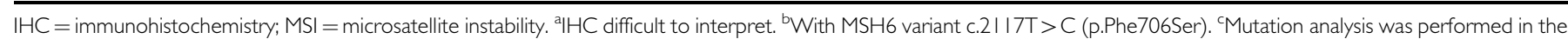
patients' brother. 
tumour DNA, a second MSI analysis in the family should always be considered to avoid missing a germline mutation because of an initial test in a phenocopy.

From previous studies we know, that in MSH6 mutation carriers CRC occurs at older age than in $M L H 1$ and $M S H 2$ mutation carriers (Hendriks et al, 2004). In our study, the patients with MSI-stable/low tumours that were analysed for MSH6 mutations were mainly diagnosed before the age of 50 . This selection is not expected to have a large influence, because MSI analysis in the families in our study is performed in the tumour of the youngest relative available. The mean age of diagnosis in MSH6 mutation carriers is above 50 , but the occurrence of one relative below 50 is expected to be present in most of the MSH6 families. The pedigrees of the diagnosed MSH6 families in our study all contained an affected relative diagnosed below 50 years of age.

The prevalence of MSH6 mutation carriers in HNPCC suspected CRC patients is low, as is demonstrated by the fact that we detected an MSH6 mutation in only about $1 \%$ of these patients. All these mutations were found in patients with an MSI-high tumour. Data from previous studies (Berends et al, 2002; Hendriks et al, 2004; Plaschke et al, 2004; Barnetson et al, 2006; Niessen et al, 2006) show that approximately $15 \%$ of colorectal tumours of $M S H 6$ mutation carriers do not have an MSI-high pattern, whereas they do show loss of MSH6 expression and thus might be the result of the MSH6 germline mutation. On the other hand, approximately $5 \%$ of colorectal tumours of MSH6 mutation carriers do show neither an MSI-high pattern nor loss of MSH6 expression and thus might have arisen independent from the genetic background of the carrier. Based on our finding of the low incidence of MSH6 mutations in HNPCC-suspected CRC patients and the percentage of non-MSI-high tumours in MSH6 mutation carriers from the literature, the probability of missing a mutation by not performing mutation analyses in patients with non-MSI-high CRCs is expected to be extremely low. This is confirmed by the fact that we did not find any non-MSI-high CRC with loss of MSH6 expression, nor a germline MSH6 mutation in any of the patients with a non-MSIhigh tumour. Our findings show that MSI analysis is highly suited to trace CRC of carriers of MSH6 germline mutations.

\section{REFERENCES}

Barnetson RA, Tenesa A, Farrington SM, Nicholl ID, Cetnarskyj R, Porteous ME, Campbell H, Dunlop MG (2006) Identification and survival of carriers of mutations in DNA mismatch-repair genes in colon cancer. N Engl J Med 354: 2751 - 2763

Berends MJ, Wu Y, Sijmons RH, Mensink RG, van der ST, Hordijk-Hos JM, de Vries EG, Hollema H, Karrenbeld A, Buys $\mathrm{CH}$, van der Zee AG, Hofstra RM, Kleibeuker JH (2002) Molecular and clinical characteristics of MSH6 variants: an analysis of 25 index carriers of a germline variant. Am J Hum Genet 70: 26-37

Boland CR, Thibodeau SN, Hamilton SR, Sidransky D, Eshleman JR, Burt RW, Meltzer SJ, Rodriguez-Bigas MA, Fodde R, Ranzani GN, Srivastava S (1998) A National Cancer Institute Workshop on Microsatellite Instability for cancer detection and familial predisposition: development of international criteria for the determination of microsatellite instability in colorectal cancer. Cancer Res 58: $5248-5257$

Hampel H, Frankel WL, Martin E, Arnold M, Khanduja K, Kuebler P, Nakagawa H, Sotamaa K, Prior TW, Westman J, Panescu J, Fix D, Lockman J, Comeras I, de la CA (2005) Screening for the Lynch syndrome (hereditary nonpolyposis colorectal cancer). N Engl J Med 352: 1851 - 1860

Hendriks YM, Wagner A, Morreau H, Menko F, Stormorken A, Quehenberger F, Sandkuijl L, Moller P, Genuardi M, Van HH, Tops C, van PM, Verkuijlen P, Kenter G, Van MA, Meijers-Heijboer H, Tan GB, Breuning MH, Fodde R, Wijnen JT, Brocker-Vriends AH, Vasen H (2004) Cancer risk in hereditary nonpolyposis colorectal cancer due to MSH6 mutations: impact on counseling and surveillance. Gastroenterology 127: $17-25$

Hoogerbrugge N, Willems R, Van Krieken HJ, Kiemeney LA, Weijmans M, Nagengast FM, Arts N, Brunner HG, Ligtenberg MJ (2003) Very low incidence of microsatellite instability in rectal cancers from families at risk for HNPCC. Clin Genet 63: 64-70

Kolodner RD, Tytell JD, Schmeits JL, Kane MF, Gupta RD, Weger J, Wahlberg S, Fox EA, Peel D, Ziogas A, Garber JE, Syngal S, nton-Culver H, Li FP (1999) Germ-line msh6 mutations in colorectal cancer families. Cancer Res 59: $5068-5074$

Lynch HT, Lynch PM (2005) Molecular screening for the Lynch syndromebetter than family history? N Engl J Med 352: 1920-1922

Niessen RC, Berends MJ, Wu Y, Sijmons RH, Hollema H, Ligtenberg MJ, de Walle HE, de Vries EG, Karrenbeld A, Buys CH, van der Zee AG, Hofstra RM, Kleibeuker JH (2006) Identification of mismatch repair gene mutations in young colorectal cancer patients and patients with multiple HNPCC-associated tumours. Gut Published on line first 24 april 2006. doi:10.1136/gut 2005.090159

Parc YR, Halling KC, Wang L, Christensen ER, Cunningham JM, French AJ, Burgart LJ, Price-Troska TL, Roche PC, Thibodeau SN (2000) HMSH6 alterations in patients with microsatellite instability-low colorectal cancer. Cancer Res 60: 2225-2231

Pinto C, Veiga I, Pinheiro M, Mesquita B, Jeronimo C, Sousa O, Fragoso M, Santos L, Moreira-Dias L, Baptista M, Lopes C, Castedo S, Teixeira MR (2006) MSH6 germline mutations in early-onset colorectal cancer patients without family history of the disease. $\mathrm{Br} J$ Cancer 95: $752-756$

Plaschke J, Engel C, Kruger S, Holinski-Feder E, Pagenstecher C, Mangold E, Moeslein G, Schulmann K, Gebert J, von Knebel DM, Ruschoff J, Loeffler M, Schackert HK (2004) Lower incidence of colorectal cancer and later age of disease onset in 27 families with pathogenic MSH6 germline mutations compared with families with MLH1 or MSH2 mutations: the German Hereditary Nonpolyposis Colorectal Cancer Consortium. J Clin Oncol 22: 4486-4494

Rodriguez-Bigas MA, Boland CR, Hamilton SR, Henson DE, Jass JR, Khan PM, Lynch H, Perucho M, Smyrk T, Sobin L, Srivastava S (1997) A National Cancer Institute Workshop on Hereditary Nonpolyposis Colorectal Cancer Syndrome: meeting highlights and Bethesda guidelines. J Natl Cancer Inst 89: 1758 - 1762

Umar A, Boland CR, Terdiman JP, Syngal S, de la CA, Ruschoff J, Fishel R, Lindor NM, Burgart LJ, Hamelin R, Hamilton SR, Hiatt RA, Jass J, Lindblom A, Lynch HT, Peltomaki P, Ramsey SD, Rodriguez-Bigas MA, Vasen HF, Hawk ET, Barrett JC, Freedman AN, Srivastava S (2004) Revised Bethesda Guidelines for hereditary nonpolyposis colorectal cancer (Lynch syndrome) and microsatellite instability. J Natl Cancer Inst 96: $261-268$

Verma L, Kane MF, Brassett C, Schmeits J, Evans DG, Kolodner RD, Maher ER (1999) Mononucleotide microsatellite instability and germline MSH6 mutation analysis in early onset colorectal cancer. J Med Genet 36: 678682

Wijnen J, De LW, Vasen H, van der KH, Moller P, Stormorken A, MeijersHeijboer H, Lindhout D, Menko F, Vossen S, Moslein G, Tops C, Brocker-Vriends A, Wu Y, Hofstra R, Sijmons R, Cornelisse C, Morreau H, Fodde R (1999) Familial endometrial cancer in female carriers of MSH6 germline mutations. Nat Genet 23: $142-144$

Wu Y, Berends MJ, Mensink RG, Kempinga C, Sijmons RH, van der Zee AG, Hollema H, Kleibeuker JH, Buys CH, Hofstra RM (1999) Association of hereditary nonpolyposis colorectal cancer-related tumors displaying low microsatellite instability with MSH6 germline mutations. Am J Hum Genet 65: $1291-1298$ 